\title{
As Características das tintas e as características dos polímeros com que são formuladas
}

\author{
S U S A A CARVALHO ${ }^{1}$, JOSÉ L UÍS NOGUEIRA ${ }^{2}$
}

\section{Resumo}

A parte mais importante do veículo fixo de uma tinta é sem dúvida constituída pelas resinas que compõem e as suas características são, também, fundamentalmente determinadas por essas mesmas resinas.

No começo do século 20 a indústria de tintas estava fortemente condicionada pelo facto de, no campo dos polímeros obtidos por via sintética, a oferta ser ainda praticamente inexistente e a escolha de veículos estar limitada aos óleos e resinas de origem natural. Essa situação foi mudando progressivamente e a partir da década de 50 deu-se um salto qualitativo importante com a introdução no mercado de homopolímeros de poliacetato de vinilo que, plastificados externamente, começaram a ser utilizados no fabrico de tintas aquosas para paredes.
Para melhorar o comportamento destas primeiras tintas cedo se começaram a utilizar copolímeros em que um dos monómeros é um monómero duro e o outro um monómero flexibilizante.

A escolha dos monómeros é fundamentalmente determinada pelas propriedades físicas e químicas necessárias no produto final e, em consequência, a maior parte das dispersões aquosas são produzidas usando mais do que um monómero para se poderem atingir as propriedades desejadas.

Nesta comunicação discute-se a relação entre os monómeros utilizados na formulação de resinas aquosas em dispersão e as características das tintas com elas formuladas e colocam-se interrogações sobre os desenvolvimentos desejáveis no futuro.

\section{Introdução}

A primeira manifestação humana que podemos dizer que está de algum modo ligada ao tema das tintas e vernizes é, sem dúvida, a pintura de animais e cenas de caça nas paredes das cavernas, as mais antigas das quais foram recentemente descobertas em cavernas usadas por trogloditas há mais de 20.000 anos atrás.

Podemos dizer que o paleolítico superior foi o berço da tecnologia das tintas que, durante muitos séculos, permanecerá, como começou, ligada à expressão artística das crenças do homem e de múltiplos aspectos da vida humana.

As tintas utilizadas pelo homem primitivo foram produzidas utilizando materiais que ele foi descobrindo enquanto prosseguia a sua actividade normal. Os primeiros desenhos nas paredes foram muito provavelmente feitos com torrões de terras coradas como quem escreve com giz num quadro preto.

A necessidade de encontrar novas cores para se exprimirem melhor levou esses primeiros artistas a procurarem outros materiais que pudessem ser usados como corantes e, naturalmente, levou à necessidade de os misturar entre si. Este facto tão simples deve ter conduzido ao uso de pigmentos em pasta em vez dos pedaços sólidos habituais. Nasceram assim, os conceitos de pigmento e verniz.

As tintas utilizadas nas pinturas rupestres começaram por ser feitas com pigmentos naturais tais como o carvão com que se obtinha a cor preta, caulinos, carbonatos e mais tarde o carbonato básico de chumbo com que se obtinham os brancos e terras coradas extraídas de depósitos naturais de óxidos de ferro, silicatos e óxidos de outros metais. Conforme a natureza e quantidade relativa dos óxidos presentes estes depósitos naturais permitiam obter vermelhos, amarelos e castanhos, nomeadamente as cores que ainda hoje se conhecem por "umbria" e "siena".

Os primeiros veículos utilizados pelo homem primitivo devem ter sido as gorduras dos animais que ele caçava e the serviam de alimento. À medida que ele foi desenvolvendo hábitos de agricultor e o conhecimento das plantas, é de presumir que começaram, também, a ser utilizados com essa finalidade sucos e óleos vegetais.

De um modo geral podemos dizer que os veículos em uso variavam muito de região para região, conforme as disponibilidades locais. O alcatrão, a clara de 
ovo, a cal, a goma-arábica e a cera de abelhas são alguns dos veículos que se tem a certeza que foram usados desde os tempos mais remotos. Os egípcios cultivavam o linho e sem dúvida conheciam as propriedades secativas do óleo de linhaça, bem como as técnicas de fabrico de vernizes formulados com óleo de linhaça e resinas duras de baixo ponto de fusão tais como o alcatrão natural, resina de aroeira e resina de sandáraca.

Com o aparecimento dos primeiros artífices e comerciantes deve ter surgido, também, a necessidade de proteger os materiais e foi com certeza esta necessidade que originou que a actividade de produção de tintas não se tivesse confinado às aplicações em pintura artística.

A revolução industrial foi, sem dúvida, o facto singular que maior pressão exerceu para o desenvolvimento da tecnologia das tintas e vernizes. $O$ aparecimento de enormes quantidades de maquinaria e estruturas de ferro a necessitar de protecção contra a corrosão constituiu um desafio enorme que levou ao estudo de tintas de qualidade e que pudessem ser produzidas na quantidade requerida pela procura existente.

O principal veículo utilizado na produção de tintas nesta época era, sem sombra de dúvida, o óleo de linhaça. Os artistas e profissionais tinham à sua disposição no mercado pastas de pigmento obtidas por moagem fina de pigmentos em óleo de linhaça e procediam depois à sua transformação em produtos acabados por adição de vernizes ou óleos vegetais e aditivos.

No começo do século 20, a indústria de tintas estava fortemente condicionada pelo facto de, no campo dos polímeros obtidos por via sintética, a oferta ser ainda praticamente inexistente e a escoIha de veículos estar limitada aos óleos e resinas de origem natural. Essa situação foi mudando progressivamente e vamos tentar dar a seguir uma curta ideia das principais modificações ocorridas neste campo na primeira metade deste século:

1907 - Resinas fenólicas;

1910 - Síntese de acetato de vinilo;
1920 - Poliacetato de vinilo em meio solvente;

1927 - Resinas alquídicas modificadas com óleo;

1930 - Borracha clorada;

1930 -1935 - Combinação de resinas alquídicas com resinas de ureia; polímeros de cloreto de vinilo;

1935 - Wash-primers formulados com butiral-polivinílico;

1940 - Resinas de melamina;

1944 - Resinas de silicone;

1946 -1950 - Poliacetato de Vinilo em meio aquoso; Estireno-Butadieno em meio aquoso;

1947 -1950 - Resinas epoxi;

1950 - Resinas de poliéster insaturadas;

1951 - Polímeros acrílicos em dispersão aquosa;

1960 - Outros polímeros em meio aquoso (VAM/VeoVa; VAM/Acrilatos; copolímeros estireno/acrilato; copolímeros acrílicos puros);
1970 - Copolímeros VAM/Etileno - copolímeros de pressão em meio aquoso.

\section{O que é uma tinta. Os seus constituintes principais.}

Se muito simplesmente recorrermos à norma portuguesa NP 41 para obtermos a definição de tinta encontramos:

TINTA - Composição pigmentada líquida, pastosa ou sólida que, quando aplicada em camada fina sobre uma superfície apropriada, no estado em que é fornecida ou após diluição, dispersão em produtos voláteis ou fusão, é convertível ao fim de certo tempo, numa película sólida, contínua, corada e opaca.

Os principais componentes de uma tinta estão representados na Caixa 1.

O veículo fixo é o responsável pela agregação dos constituintes da tinta e determina, por esse facto, o comportamento da tinta no que se refere a características como:

- Propriedades mecânicas (p.e. elasticidade);

- Resistência à intempérie e à radiação UV

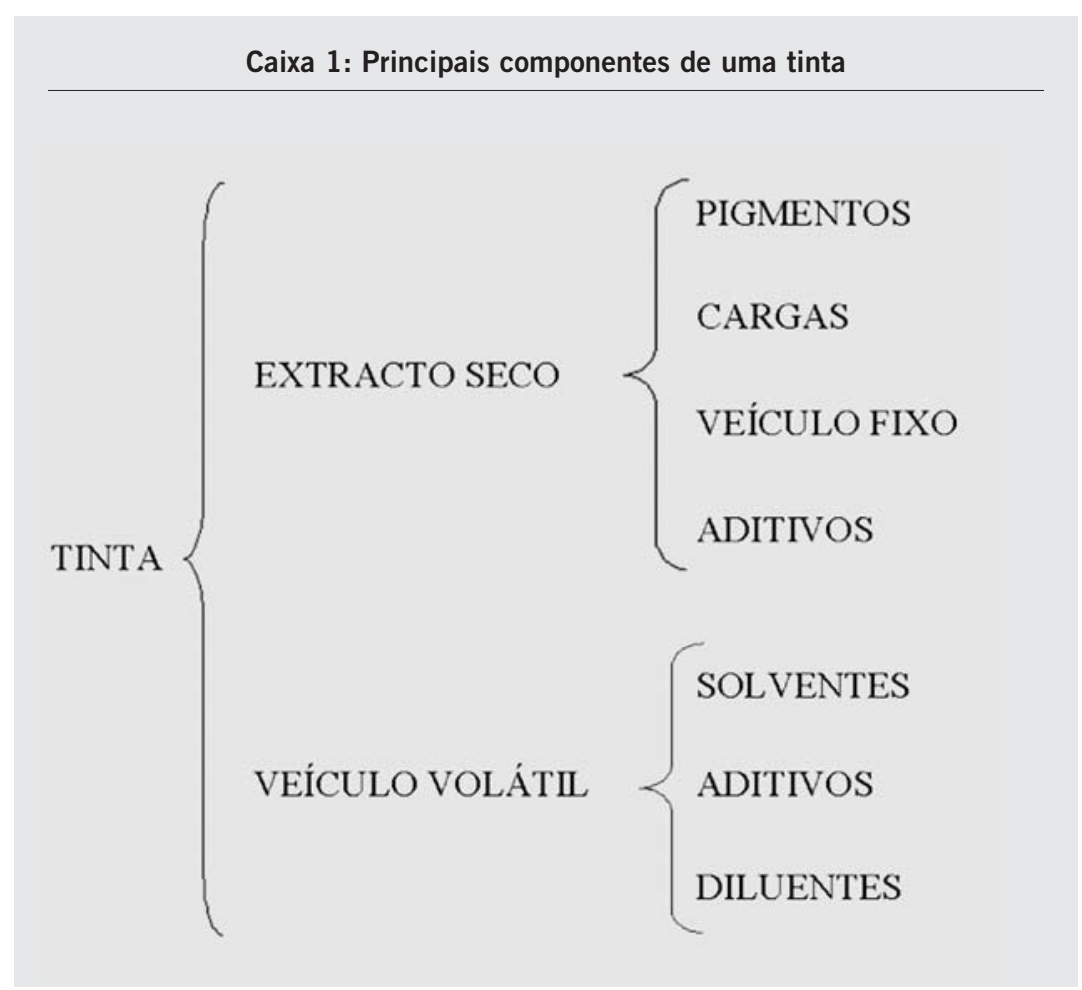


- Resistência química (p.e. à alcalinidade);

- Brilho;

- Pegajosidade superficial e resistência ao bloqueamento.

A relação entre o veículo e os pigmentos e cargas é um parâmetro essencial na diferenciação das tintas. Uma vez que as tintas são aplicadas em camadas tridimensionais, esta relação é traduzida em termos de volume e toma a designação de CPV - Concentração de Pigmentos em Volume (ou PVC, como é mais frequentemente conhecida, da designação em inglês - Pigment Volume Concentration). A CPV é expressa em percentagem e corresponde ao quociente entre o somatório do volume de cargas $\left(V_{c}\right)$ e pigmentos $\left(V_{p}\right)$ e o somatório do volume de cargas, pigmentos e veículo $\left(V_{L}\right)$, também designado por ligante:

$$
C P V[\%]=\frac{\mathrm{V}_{\mathrm{P}}+\mathrm{V}_{\mathrm{C}}}{\mathrm{V}_{\mathrm{P}}+\mathrm{V}_{\mathrm{C}}+\mathrm{V}_{\mathrm{L}}} \times 100
$$

As tintas muito ricas em veículo, após evaporação dos voláteis, apresentam um filme contínuo de ligante no qual se distribuem os pigmentos e cargas. Neste caso a CPV da tinta é baixa, geralmente inferior a $45 \%$, conforme se pode ver na figura 1 .

Por outro lado as tintas pobres em ligante apresentam filmes porosos, nos quais predominam os pigmentos e cargas, sendo o ligante apenas o elemento aglutinador entre estes constituintes, não chegando a sua quantidade para preencher os espaços livres, como se pode observar na figura 2. Estas tintas têm CPVs acima de $70 \%$.

A parte mais importante do veículo fixo de uma tinta é sem dúvida constituída pelos óleos e resinas que o compõem e as suas características são, também, fundamentalmente determinadas por essas mesmas resinas. Daí que seja comum utilizar o nome da resina que compõem o veículo fixo ao caracterizar os sistemas de pintura, pois as suas propriedades estão indissoluvelmente ligadas às dos veículos com que estão formulados os produtos que o constituem, nomeadamente as tintas de acabamento.

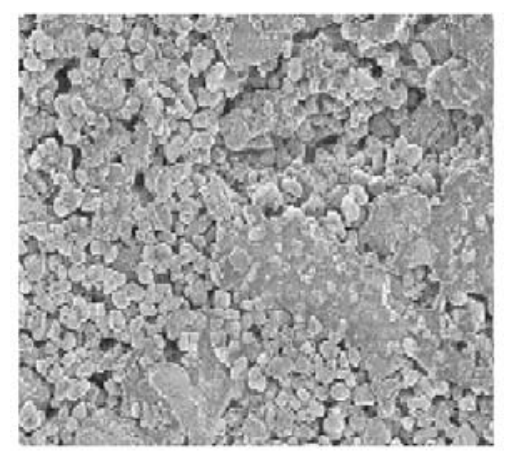

figura 1 Fotografia obtida por microscopia electrónica de tinta abaixo da CPV crítica.

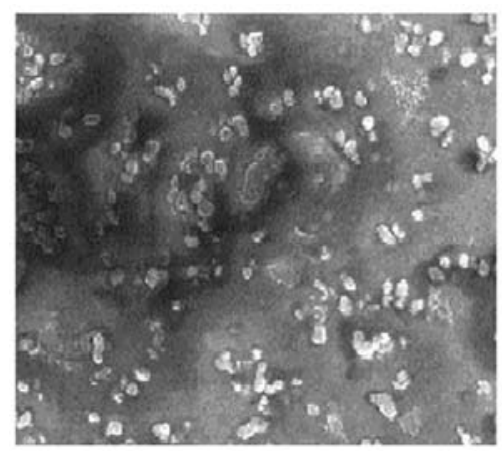

figura 2 Fotografia obtida por microscopia electrónica de tinta acima da CPV crítica.

A referência a todos os veículos que têm utilização na indústria de tintas e vernizes levar-nos-ia a escrever um livro. Neste artigo vamos pois limitar-nos a discutir alguns aspectos relacionados com os polímeros que têm utilização corrente em tintas para arquitectura, nomeadamente tintas de base aquosa para a pintura de paredes em interior e exterior.

\section{Polímeros em emulsão aquosa}

As dispersões de resinas podem ser preparadas de duas maneiras distintas: uma por polimerização em emulsão e outra por emulsificação posterior da resina. Tal como o próprio termo indica, a polimerização em emulsão é um conjunto de dois processos distintos conduzidos numa só operação: a polimerização para transformação do monómero no polímero e a emulsificação deste.

A emulsificação posterior da resina envolve somente a emulsificação propriamente dita uma vez que se parte de uma resina que se obteve previamente de fontes naturais ou por polimerização usando reacções de adição ou condensação.
No processo em emulsão a polimerização ocorre em pequenas micelas (cerca de 0,01 $\mu \mathrm{m}$ ), dispersas em meio aquoso, formadas por surfactante, monómero e polímero em crescimento. Estão ainda presentes gotículas de monómero de tamanho superior ( $1 \mu \mathrm{m})$, que funcionam como "reservatórios" para fornecimento de monómero às cadeias em crescimento nas micelas. Os monómeros vulgarmente usados na produção de dispersões aquosas contêm obrigatoriamente uma ligação dupla entre dois átomos de carbono. É à custa da quebra desta ligação dupla e formação de duas ligações simples, que se vai dar o crescimento do polímero - reacção de poliadição.

Devido às boas condições de transferência de calor através da fase aquosa, o calor de polimerização pode ser removido facilmente e a polimerização processa-se rapidamente. Por outro lado, uma vez que o polímero não é solúvel na fase contínua (água), o comprimento do polímero, isto é, o seu peso molecular não influencia a viscosidade do produto. Estes dois factores, a facilidade de transferência de calor através da fase aquosa, bem como o facto da viscosidade da dispersão ser independente do 
Caixa 2 - Monómeros mais comuns

\begin{tabular}{ll}
\hline Monómero & Fórmula \\
Acetato de vinilo (VAM) & $\mathrm{CH}_{3} \mathrm{COOCH}=\mathrm{CH}_{2}$ \\
Butadieno & $\mathrm{CH}_{2}=\mathrm{CH}-\mathrm{CH}=\mathrm{CH}_{2}$ \\
Acrilato de Butilo (BA) & $\mathrm{CH}_{2}=\mathrm{CH}-\mathrm{COOC}_{4} \mathrm{H}_{9}$ \\
Acrilato de 2-etilhexilo (EHA) & $\mathrm{CH}_{2}=\mathrm{CH}-\mathrm{COOC}_{8} \mathrm{H}_{17}$ \\
Cloreto de vinilo & $\mathrm{CH}_{2}=\mathrm{CH} \mathrm{Cl}$ \\
Dibutil maleato & $\mathrm{CH}_{-} \mathrm{COOC} \mathrm{H}_{9}$ \\
& $\mathrm{I}$ \\
& $\mathrm{CH}_{-} \mathrm{COOC} \mathrm{H}_{9}$ \\
Estireno & $\mathrm{C}_{6} \mathrm{H}_{5} \mathrm{CH}=\mathrm{CH}_{2}$ \\
Etileno & $\mathrm{CH}_{2}=\mathrm{CH}_{2}$ \\
Metacrilato de Metilo & $\mathrm{CH}_{2}=\mathrm{C}\left(\mathrm{CH}_{3}\right)-\mathrm{COOCH}{ }_{3}$ \\
Versatato de Vinilo (VeoVa 10) & $\mathrm{CH}_{3} \mathrm{C}\left(\mathrm{R}_{1}\right)\left(\mathrm{R}_{2}\right)$ CoOCH $=\mathrm{CH}_{2}$ \\
& $\left(\mathrm{R}_{1}\right.$ e R $\mathrm{R}_{2}$ são grupos alquilo \\
& que no seu conjunto possuem \\
& 7 átomos de carbono) \\
&
\end{tabular}

peso molecular do polímero, permitem a produção de polímeros de alto peso molecular.

Alguns dos monómeros mais frequentemente utilizados são referidos na Caixa 2.

O processo de polimerização começa com a dissociação do iniciador em radicais livres. Na fase seguinte, estes colidem com as moléculas do monómero, dando origem a novos radicais livres mais complexos que continuam a combinar-se com outras moléculas de monómero até formarem um polímero de cadeia comprida.

A fase final ou de termo pode ocorrer pela combinação de duas cadeias em crescimento, combinação de uma cadeia em crescimento com um radical livre, etc. Com monómeros com funcionalidade dois (uma dupla ligação por molécula), formam-se polímeros lineares. Quando se introduzem moléculas com uma funcionalidade maior do que dois, pode ocorrer a formação de polímeros com cadeias laterais e reticuladas.

Uma dispersão aquosa no final do processo de polimerização pode represenços; se combinado com o dibutil malea- to produz polímeros menos duros e muito mais elásticos.

Muito frequentemente usam-se monómeros especiais na fabricação de polímeros para se obterem propriedades específicas. Tal é o caso, por exemplo, da inclusão de pequenas quantidades de ácido para melhorar a estabilidade ao gelo - degelo e a adição de etileno para melhorar a aderência a certos materiais.

Pelo que atrás ficou dito se vê que a escolha dos monómeros mais adequados é uma tarefa muito complicada; para além do comportamento final dos polímeros outros factores tais como o custo, a facilidade de produção e a estabilidade em armazém, por exemplo, têm também que ser considerados e convém salientar que mesmo uma escolha criteriosa dos monómeros pode conduzir a um mau polímero, pois o tamanho de partícula, a tensão superficial e outras características têm uma influência importante no comportamento final do produto.

\section{Homopolímeros}

Os homopolímeros de acetato de vinilo (VAM) foram dos primeiros polímeros em emulsão aquosa a serem utilizados para o fabrico de tintas de arquitectura. Como o acetato de vinilo é um polímero duro, isto é, os filmes de polímero à temperatura ambiente são quebradiços, tinham que ser plastificados utilizando plastificantes externos, dos quais o mais utilizado foi seguramente o ftalato de dibutilo.

As tintas assim formuladas utilizavam-se muito há cerca de 40 anos. Foram substituídas devido à baixa resistência à água e aos alcalis e ao facto de com o tempo perderem a flexibilidade e fissurarem devido à perda progressiva do plastificante externo por evaporação.

Actualmente em Portugal quase só se utilizam no fabrico de massas para obtenção de efeitos decorativos especiais.

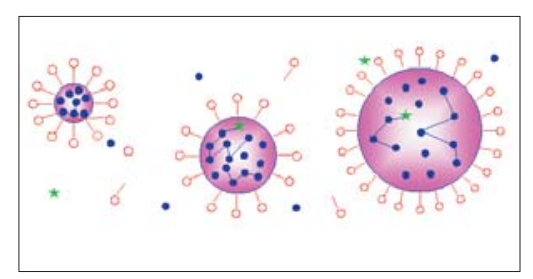

figura 3 Representação esquemática de um polímero em emulsão aquosa na fase final de polimerização. 
Utilizam-se ainda hoje em outros países para o fabrico de tintas fundamentalmente para interior e são difíceis de substituir por uma razão inesperada: o cheiro suave e adocicado do poliacetato de vinilo que os profissionais associam a produtos que utilizaram frequentemente ao longo da sua vida profissional e que, portanto, resistem a substituir.

\section{Copolímeros de acetato de vinilo}

A abordagem de copolimerizar vários monómeros com o acetato de vinilo surgiu da necessidade de melhorar as características de flexibilidade e resistência à alcalinidade dos homopolímeros de acetato de vinilo.

Os monómeros mais utilizados para este fim foram os acrilatos, nomeadamente 0 acrilato de butilo e o acrilato de 2-etilhexilo, e o versatato de vinilo (VeoVa 10).

O parâmetro que é utilizado para avaliar a dureza/flexibilidade dos polímeros de um dado monómero é a temperatura de transição vítrea (Tg). Esta grandeza traduz a temperatura à qual um dado homopolímero passa do estado vítreo a fluido viscoso e quanto mais baixa for, mais macio é o polímero. Alguns exemplos encontram-se na Tabela 1.

Através da copolimerização de VAM com os monómeros de Tg mais baixa consegue-se um efeito de plastificação interna. Na prática isto traduz-se em películas mais macias e que não perdem as suas características ao longo do tempo, uma vez que o agente que vai plastificar o polímero é ele próprio um monómero polimerizado que é parte integrante do polímero. Os exemplos de copolímeros de VAM e acrilatos ilustram este efeito (Tabela 2).

Em termos de resistência à alcalinidade, também a utilização de copolímeros pode ser avaliada, como se demonstra com os resultados de percentagem de saponificação de copolímeros de acetato de vinilo (Tabela 3).

A maior resistência à alcalinidade dos copolímeros VAM/VeoVa relativamente aos VAM/acrilatos resulta essencialmente de uma distribuição mais homogénea dos dois monómeros nos VAM/VeoVa, uma vez que ambos os monómeros têm como centro reactivo um grupo vinílico e por isso com reactividade semelhante. No caso dos VAM/acrilatos, os monómeros têm, respectivamente, um grupo vinílico e um acrílico como centros reactivos. As reactividades cruzadas destes grupos são diferentes e por isso a distribuição do monómero acrílico não é uniforme ao longo do filme, originando zonas de maior fragilidade ao ataque pelos alcalis.

Resumindo o efeito da plastificação interna com a do aumento da resistência à alcalinidade conferidos pela copolimerização de outros monómeros com o acetato de vinilo, conclui-se que os acrilatos mencionados são mais eficientes na redução da Tg do copolímero, isto é, conferem maior elasticidade ao filme de polímero do que o VeoVa, mas que este último é mais eficiente no aumento da resistência à alcalinidade do que os acrilatos.
Esta constatação explica de alguma forma as diferentes tendências que se observam nos mercados europeu e norte-americano em termos de utilização de ligantes.

Na Europa, as tintas formuladas com VAM/NeoVa vieram substituir os homopolímeros VAM essencialmente nas tintas de média e alta qualidade para interior e exterior, cobrindo uma larga gama de CPVs e brilhos. Actualmente são usados na formulação de tintas até CPVs de 70\%. A sua excelente resistência à alcalinidade é um requisito fundamental, uma vez que os substratos usados na Europa são minerais (argamassas de cimento, estuques).

Na América do Norte as casas de habitação eram (e continuam ainda a ser) tradicionalmente construídas em madeira, pelo que o efeito da flexibilidade do filme de polímero é um requisito mais importante do que o da resistência à al-

\section{Tabela 1 - Temperatura de transição vítrea (Tg) do homopolímero}

\begin{tabular}{lc}
\hline Monómero & Tg do homopolímero $\left({ }^{\circ} \mathrm{C}\right)$ \\
\hline Acetato de vinilo & 30 \\
Acrilato de butilo & -54 \\
Acrilato de 2-etilhexilo & -85 \\
VeoVa 10 & -2 \\
\hline
\end{tabular}

Tabela 2 - Copolimerização de VAM com monómeros de baixa Tg.

\begin{tabular}{ccc}
\hline Polímero & Composição $(\%)$ & $\operatorname{Tg}\left({ }^{\circ} \mathrm{C}\right)$ \\
\hline VAM/EHA & $85 / 15$ & 10 \\
VAM/BA & $83 / 17$ & 10 \\
\hline
\end{tabular}

Tabela 3 Percentagem de saponificação de copolímeros de acetato de vinilo

\begin{tabular}{cccc}
\hline \% Comonómero & VeoVa & BA & EHA \\
\hline 0 & 91 & 91 & 91 \\
10 & 41 & 68 & 56 \\
20 & 19 & 42 & 28 \\
30 & 11 & 28 & 21 \\
\hline
\end{tabular}


Tabela 4 Variação das propriedades físicas e químicas em função do tipo de co-monómero utilizado.

\begin{tabular}{|c|c|c|c|c|}
\hline Homopolímero & Dureza & Flexibilidade & Resistência aos U.V. & Resistência aos alcalis \\
\hline Estireno & & & Baixa & Excelente \\
\hline Acrilonitrilo & & & Razoável & Baixa \\
\hline Metacrilato de metilo & $\Lambda$ & П & Muito boa & Muito boa \\
\hline Metacrilato de etilo & & & Exelente & Excelente \\
\hline Metacrilato de butilo & & \} & Exelente & Excelente \\
\hline Acrilato de metilo & & & Baixa & Muito boa \\
\hline Acrilato de etilo & & & Razoável & Muito boa \\
\hline Acrilato de butilo & & & Muito boa & Muito boa \\
\hline Acrilato de 2-etilhexilo & & & Boa & Muito boa \\
\hline
\end{tabular}

calinidade. Os ligantes mais usados são os VAM/acrilatos. Para aplicações mais exigentes são usados polímeros acrílicos puros.

\section{Copolímeros Acrílicos}

Os copolímeros acrílicos são uma importante classe de copolímeros que parte do mesmo princípio de utilização de um monómero duro e um monómero macio.

Os monómeros macios mais utilizados são os anteriormente referidos. Os monómeros duros mais frequentes são o estireno $\left(\mathrm{Tg}=107^{\circ} \mathrm{C}\right)$, sendo os copolímeros assim obtidos designados por estireno/acrílicos ou ele próprio um acrilato, como seja o metacrilato de metilo ( $\mathrm{Tg}$ $=105^{\circ} \mathrm{C}$ ), obtendo-se polímeros acrílicos puros.

Para além dos parâmetros de elasticidade e resistência à alcalinidade anteriormente referidos, os copolímeros acrílicos são também avaliados em termos da resistência aos raios ultravioleta (UV) que, por sua vez, determina a resistência à intempérie. Nesta última característica os copolímeros contendo quantidades apreciáveis de estireno têm baixos desempenhos, o que condiciona a utilização de copolímeros estireno/acrílicos em tintas para exterior.

Por outro lado, a excepcional resistência à alcalinidade do estireno permite a formulação de tintas para interior de altas
CPVs (baixos teores em ligante) mas com boas características de resistência à lavagem. Assim, os polímeros estireno/acrílicos são muito utilizados para a formulação de tintas com CPVs acima de $70 \%$.

Os copolímeros acrílicos puros aliam as várias características de elasticidade, resistência à alcalinidade e resistência à intempérie, o que faz deles os utilizados para as aplicações mais exigentes de tintas para exterior. São usados em geral em formulações com baixas CPVs.

A versatilidade dos polímeros acrílicos em termos da selecção de propriedades que advêm da utilização dos diferentes acrilatos faz deles os ligantes de eleição para as aplicações industriais, mais exigentes do que as aplicações em tintas decorativas. De facto, os copolímeros acrílicos puros são já largamente utilizados como ligantes em revestimentos para madeira, plástico e metal (protecção anticorrosiva).

Na tabela 4, resumem-se as propriedades de dureza/flexibilidade, bem como de resistência à radiação UV e à alcalinidade dos monómeros mais utilizados na produção de ligantes estireno/acrílicos e crílicos puros.

\section{Futuro}

Mesmo o cidadão menos atento já se apercebeu da crescente importância dos movimentos ecologistas, o que, na- turalmente, traduz a preocupação crescente das pessoas em geral com a qualidade do ar, da água e de todo o meio ambiente que as cerca. As últimas investigações tendem a demonstrar que se pode obter uma redução importante da poluição foto-oxidante pela simples redução das emissões de compostos orgânicos voláteis (COVs ou em inglês vocs de volatile organic compounds) e é por isso que hoje em dia existem em quase todos os países planos para limitar essas emissões.

A indústria de tintas é, directa e indirectamente, uma fonte importante de poluição, entre outras razões, pela emissão de quantidades importantes de solventes para a atmosfera. Fácil é concluir-se que vai estar sujeita cada vez mais a pressões para que esse problema se resolva. Exemplos claros disso são a publicação recente de Directivas Comunitárias como a Directiva 1999/13/CE e a Directiva 2004/42/CE que obrigam à redução do conteúdo dos solventes nas tintas. Essa redução far-se-á, muito provavelmente, mediante a introdução de novas tecnologias uma das quais, e talvez a mais promissora, é a da generalização da utilização de produtos de base aquosa.

As tintas aquosas para fins decorativos estão já bem introduzidas em algumas áreas, com as tintas de emulsão para paredes. 
Mais difícil tem sido a introdução de tintas de base aquosa na indústria e para substituir os esmaltes decorativos nas tintas de arquitectura. Essas dificuldades resultam fundamentalmente de as tintas aquosas possuírem preços mais elevados, baixo brilho e serem difíceis de aplicar, nomeadamente, pela dificuldade de cobrir convenientemente as arestas, devido a fenómenos de tensão superficial ainda não resolvidos. É de admitir que se dê nos próximos 5 anos o grande salto em frente para os produtos aquosos.

Como já atrás referimos, com o aumento das restrições à emissão de solventes nos revestimentos decorativos e repintura automóvel, cujo primeiro passo se avizinha já em 2007 com a implementação da primeira fase da directiva 2004/042/CE , é de esperar um forte incremento na utilização de polímeros em emulsão aquosa em geral e no aparecimento de novos polímeros que satisfaçam as novas exigências do mercado.

Uma nova classe de polímeros que vem encontrando utilização para a formulação de tintas isentas de emissão são os copolímeros de VAM e etileno. O etileno é um monómero gasoso extremamente macio que diminui muito eficientemente a Tg do polímero. Permite por isso a formulação de produtos cuja película é formada à temperatura ambiente sem necessidade de recorrer a adjuvantes de filmificação (coalescentes de filme) que são solventes e, por isso, contribuem para o aumento de compostos orgânicos voláteis na atmosfera. Os polímeros de VAM/etileno são obtidos através da polimerização sob pressão, uma vez que o etileno é um gás à pressão atmosférica.

Outra classe de polímeros que tem interessado muito os investigadores é a dos polímeros que permitam obter um tempo aberto e um brilho final elevados. Este tipo de polímeros tem sido alvo de um enorme desenvolvimento, recorrendo à introdução de pequenas quantidades de co-monómeros funcionais bem como à modificação da sua morfologia, o que permitiu a obtenção de produtos de base aquosa com melhores desempenhos na aplicação; mas a realidade é que algumas características fortes dos produtos de base solvente tais como, tempo aberto, corpo, lacagem ou brilho, são ainda difíceis de igualar com produtos de base aquosa. São, no entanto, conhecidos alguns avanços no estudo de novas resinas que fazem supor que estes problemas serão resolvidos, de forma satisfatória, muito em breve.

Qualquer que seja a nossa visão sobre como vai evoluir a sociedade humana num futuro próximo, penso que será facilmente aceite por todos que, nas áreas dos polímeros e das tintas a que temos vindo a referir-nos, as linhas de desenvolvimento a seguir descritas farão parte dessa evolução:

- aceleração do processo de automatização das operações de fabrico;

- desenvolvimento de novos produtos com maior compatibilidade com superfícies menos bem preparadas, maior facilidade de aplicação com métodos convencionais e melhor adaptação à aplicação com métodos automáticos;

- desenvolvimento de novos produtos com secagem mais rápida e maior compatibilidade com condições atmosféricas adversas;

- desenvolvimento de novos produtos com maior compatibilidade com novos materiais, nomeadamente novos plásticos e materiais cerâmicos;

- desenvolvimento de novas tecnologias que permitam a utilização de esquemas de pintura mais simples, em particular no que respeita ao número total de demãos;

- desenvolvimento de novos produtos com maior durabilidade.

A satisfação destas necessidades pode passar, por exemplo, pela modificação de copolímeros acrílicos com monómeros tradicionais dos produtos de base solvente e que possam sofrer um processo de cura oxidativo após a evaporação da água, tornando as películas de tinta mais resistentes e mantendo o tempo aberto mais elevado. Esta é uma abordagem que já está em curso e que pode contribuir decisivamente para o desenvolvimento de novos produtos nestas áreas.
Deixamos aqui algumas pistas que podem inspirar não só o trabalho dos químicos na indústria, mas também o trabalho de investigadores nas Universidades como contributo para a tão discutida e desejada maior aproximação entre a indústria e o meio académico universitário.

\section{Bibliografia}

Clive H. Hare, Anatomy of Paint, Journal of Protective Coatings and Linings, October 1990.

G.G. Shurr, Exterior House Paint, Federation Series on Coatings Technology, Unit 24, 1977.

G.P.A. Turner, Introduction to Paint Chemistry and Principles of Paint Technology, Science Paperbacks- Chapman and Hall, 1980

Guy E. Weismantel, Paint Handbook, McGraw-Hill Book Company., 1981

Joe Maty, In the 40's. Wartime Rubber Crunch gives Bounce to Fledging Science of Latex Resins, Paint and Coatings Industry, August 2004.

M. Schwartz, R. Baumstark, Waterbased Acrylats for Decorative Coatings, Ulrich Zorll, 2001.

P. Oldring et al, Resins for Surface Coatings, SITA Technology, 1987.

Peter Johns et al, Waterborne \& Solvent Based Surface Coating Resins and Their Applications, Sita Technology Ltd, 1996.

Pierre Grandou, Paul Pastour, Peinture et Vernis, Hermann, 1969.

S.R. Finn, Introduction to Paint Technology, Oil and Colour Chemists Association, 1976.

T. C. Patton, Alkyd Resin Technology, Interscience, 1962.

W.M. Morgans, Outlines of Paint Technology, Charles Griffin and Company Limited, 1984.

Wayne R. Fuller, Formation and Structure of Paints Films, Federation of Societies for Coatings Technology, 1965.

Wayne R. Fuller, Introduction to Coatings Technology, Federation of Societies for Coatings Technology, 1973.

Mowilith Handbook 5. ${ }^{a}$ edição, Farbwerke Hoechst AG, 1972.

Resinas Sintéticas e Matérias Primas para Vernizes, Hoechst AG, 1994.

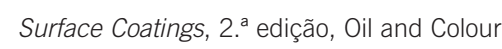
Chemists Association, 1983 